\title{
Cimetidine in the Treatment of Acute Intermittent Porphyria from Onset to Death
}

Yanyan Xie, Zhenyu Yan ${ }^{*}$, Linhong Wang, Bing Yan, Zhaoling Deng and Naiyao Chen

Department of Hematology, Affiliated Hospital of North China University of Science and Technology, Tangshan, 063000, China

*Corresponding author: Yan Zhenyu, Department of Hematology, Affiliated Hospital of North China University of Science and Technology, Tangshan, 063000, China, Tel: 0315-2592044; E-mail: hbyzy2011@163.com

Received date: Sep 24, 2015, Accepted date: Dec 29, 2015, Publication date: Dec 31, 2015

Copyright: $\odot 2015$ Xie Y, et al. This is an open-access article distributed under the terms of the Creative Commons Attribution License, which permits unrestricted use, distribution, and reproduction in any medium, provided the original author and source are credited.

\begin{abstract}
Acute intermittent porphyria (AIP) is a rare, frequently misdiagnosed disease characterized by abdominal pain and psychiatric symptoms. Abdominal pain is the most common. At present, there is no radical cure for AIP. Hematin is considering the effective treatment to relieve the symptom. However, it is not available in china. A 25-year-old Chinese woman complained about intermittent abdominal pain for 2 years. He was misdiagnosed as acute abdominal disease many times. During attacks, abdominal pain relief always took more than 1 week without effective treatment. In our hospital, the patient was diagnosed AIP definitely and treated with intravenous cimetidine 400mg Q6h, symptoms especially abdomen pain relieved within 48-72 hours completely in each acute attack. Few cases of cimetidine to treat AIP have been reported. More clinical date is required in order to verify whether the routine treatment of cimetidine can replace hematin or be used as a preventive treatment. This is the first case to report that cimetidine has obvious effect during AIP acute attacks.
\end{abstract}

Keywords: Cimetidine; Acute intermittent porphyria

\section{Introduction}

Acute intermittent porphyria (AIP) is the most common type of porphyria which is a group of inherited or acquired metabolic diseases, attributed to defect of porphobilinogen deaminase (PBGD) in heme synthesis pathways resulting in overproduction of toxic hemin precursors such as hepatic $\delta$-aminolevulinate (ALA) and porphobilinogen $(\mathrm{PBG})[1]$. The principle of treating AIP is to reduce the hepatic $\delta$-aminolevulinate synthetase (ALAS) activity [2]. At present, there is no radical treatment for the disease and hematin is the first choice when acute AIP attacks. However, hematin is not readily available in China and therefore only symptomatic and supportive treatments could be administered, improving the clinical symptoms very slowly. Cimetidine has been shown effective in the treatment of AIP. We herein report the first case of a patient with recurrent AIP attacks who was treated with cimetidine successfully in China. The aim of this letter is to confirm that cimetidine has obvious effect during AIP acute attacks.

\section{Case Report}

A 25-year-old Chinese woman complained about intermittent abdominal pain for 2 years. During the 2 years, her recurrent abdominal pain, accompanied with intestinal obstruction sometimes, was treated at a local hospital where frequent exploratory laparotomies were performed, leaving multiple scars on the abdomen without positive findings. She had not received diagnosis and treatment. Abdominal pain relief always took more than 1 week every time. The patient was presented to our Department of General Surgery with complain of abdominal pain accompanied by cessation of exhaustion and defecation on December 7, 2008 for the first time.
Her pulse was $160 \mathrm{bpm}$ and blood pressure was $150 / 95 \mathrm{mmHg}$. Abdominal tenderness was found during physical examination, but no muscle tension. Laboratory examination revealed the blood cells count, kidney function and liver function were normal. Mild hyponatremia was detected. Urine darkening by exposure to sunlight was observed when abdominal pain attacked. Further analysis of the patient's urine showed PBG and FEP (free erythrocyte protoporphyrin) positive, and uroporphyrin negative, the results consistent with acute porphyria. PBGD activity was not detected due to lack of related instruction. In terms of family history, her mother and an uncle suffered from psychosis. The patient was diagnosed with acute intermittent porphyria finally.

We started therapies with intravenous infusions of cimetidine, 400 mg Q6h. The second day, her pain had a relief, and 2 days later, the clinical symptoms including cessation of exhaustion and defecation achieved complete remission. It should be noted that 2 days before the application of cimetidine, supportive treatment had been ineffective. High concentration glucose therapy was also given. The patient was discharged after 2 weeks of continued treatment of cimetidine with gradual dose reduction. As the patient could not tolerate oral cimetidine daily at home, oral prophylaxis for only 7 days before menstruation was prescribed, considering her first acute attack was triggered by menstruation. In the next 1 year, the patient experienced 6 clinical episodes of severe abdominal pain, triggered by drugs, mood or tiredness. Fortunately, symptoms were relieved within 48-72 hours after cimetidine treatment every time. However, in the last attack, the patient had already been unconscious when she was hospitalized due to the acute attack which had started at least 10 days before. The urine analysis indicated renal failure and sever electrolyte disorder. The patient's heart rate and blood pressure dropped quickly and she was transferred to the Intensive Care Unit where she died from multiple organ failure after 2 days. This patient experienced 15 months from the onset of the disease to her death. General characteristics of the patient on admission see the Table 1. 
Page 2 of 3

\begin{tabular}{|l|l|l|l|}
\hline Date & Chief compliant & Triggering factor & Symptom remission(h) \\
\hline $7 / 12 / 2008$ & Abdominal pain, cessation of exhaustion and defecation & Menstruation & 72 \\
\hline $5 / 3 / 2009$ & Abdominal pain ,cessation of exhaustion and defecation & Mood & 72 \\
\hline $30 / 4 / 2009$ & Abdominal pain & Drug(Asprin) & 48 \\
\hline $4 / 7 / 2009$ & Abdominal pain & Mood & 48 \\
\hline $21 / 8 / 2009$ & Abdominal pain & Tiredness & 48 \\
\hline $25 / 11 / 2009$ & Abdominal pain & Drug(Acetaminophe) & 72 \\
\hline $9 / 3 / 2010$ & Abdominal pain, unconscious & Mood & Death \\
\hline Symptom remission(h): After administration of cimetidine & & \\
\hline
\end{tabular}

Table 1: General characteristics of the patient on admission.

\section{Discussion and Conclusion}

AIP is a rare autosomal dominant disorder with the incidence of affecting 1 to 2 in 10,000 [3]. The clinical manifestations of this syndrome are characterized by extreme variability with a severe abdominal pain. Clinically, it is easy to be misdiagnosed as intestinal obstruction, as it is often accompanied by cessation of exhaustion and defecation. The entire number of patients recommended for clinical investigations need to go through repeated inspection and exclusion before final diagnosis.

AIP attacks can be usually triggered due to different factors, including increase in cytochrome P450 expression that regulates ALAS activity due to drugs, and alcohol that also results in mood disorders, endocrine and metabolic disorders [3]. Menstruation is an important predisposing factor that we have observed among the patient under study. It might be one of the reasons why women of productive age are more prone to get affected due to this disease than men. Consequently, avoiding these underlying triggering factors is key to prevent acute attacks.

The conventional therapy of AIP includes glucose loading and other supportive treatment. However, symptom improvement may take a long time. Hematin is considered as the first choice during AIP acute attacks. It is undeniable that the effect of Hematin is to reduce the activity of ALAS, thereby preventing the progression of clinical symptoms or biochemical results [4]. Jones et al. reported that abdominal pain can be relieved within 15 minutes of administering Hematin [5]. However, Hematin is also a palliative and it is difficult to acquire in China. In addition, thrombophlebitis and renal failure have been reported [4-6]. In contrast, Cimetidine is a cheap and easy to obtain a medicine and its effectiveness has been proved in many cases, and it is within the reach of the [patients in every aspect.

Cimetidine, a histamine $\mathrm{H} 2$ receptor antagonist with the effect of inhibiting gastric acid secretion, was developed to treat peptic ulcers. Surprisingly, porphyria, including erythropoietic protoporphyria (EP) [7], porphyria cufanea tarda (PCT) [8] can also be used to control and AIP effectively [9]. Cimetidine can decrease ALAS activity directly. In addition, through inhibiting cytochrome P450 mediated drug metabolism it reduces heme oxygenase activity. Heme consumption can be declined to reduce ALAS activity indirectly by negative feedback [10]. Horie et al. reported that Cimetidine can be used to treat primary as well as recurrence AIP cases effectively. Administering
Cimetidine orally decreases urine ALA and PBG excretion rapidly to the normal stage [11]. The present case study proves that intravenous administration of Cimetidine and glucose loading has proved very effective in relieving symptoms; especially the abdomen pain was relieved completely within 48-72 hours. The urine PBG or ALA was not dynamically monitored in the acute cases due to financial reasons.

Acute renal failure is the most serious complication among acute intermittent Porphyria patients. Vomiting or diarrhea may lead to Hypovolemia and pre-renal failure in some cases. However, patients that have participated in this study had a 2 -year clinical history prior to its diagnosis without appropriate treatment. The patient experienced of recurrent episodes of pain. This may have played an important role in the impairment of renal function and contributed to her death due to the deposit of toxic substances in renal tubules during acute attacks. The contribution of Hematin and Cimetidine to enhance the survival of the patients affected with AIP is unclear yet due to lack of research in this direction.

To our knowledge, this is the only case treated with Cimetidine ever since the onset of the disease till the death of the patient, through which the effect of Cimetidine was thoroughly monitored. Although Cimetidine has obvious effects on AIP acute attack, the interval between each attack seems not affected. Cherem et al. [12] documented the case history of 4 patients managed with the oral administration of Cimetidine $800 \mathrm{mg}$ daily for 1-year and the followup showed only 1 attack episode in some patients while the others did not experience any attack. This could demonstrate the promising efficacy of this drug in preventing the attack. The effect of preventive treatment however needs further investigation. The patient participated in the present study had been given oral Cimetidine 800 mg daily, 7 days ahead of the menstruation cycle and thereafter. The acute attack did not happen in her menstrual period, indicating the prophylaxis effect on her acute attacks $[12,13]$. More clinical data is required to verify whether the routine application of Cimetidine can be replaced with Hematin as preventive medicine.

\section{Conflict of Interest}

The authors declare that they have no conflict of interest.

\section{References}

1. Puy H, Gouya L, Deybach JC (2010) Porphyrias. Lancet 375: 924-937. 
Citation: Xie Y, Yan Z, Wang L, Yan B, Deng Z, et al. (2015) Cimetidine in the Treatment of Acute Intermittent Porphyria from Onset to Death. J Blood Disord Transfus 6: 331. doi:10.4172/2155-9864.1000331

Page 3 of 3

2. Bissell DM, Lai JC, Meister RK, Blanc PD4 (2015) Role of deltaaminolevulinic acid in the symptoms of acute porphyria. Am J Med 128 313-317.

3. Syal K, Bhatt R, Singh S, Ohri A1 (2015) Acute intermittent porphyria. J Anaesthesiol Clin Pharmacol 31: 261-263.

4. Dhar GJ, Bossenmaier I, Petryka ZJ, Cardinal R, Watson CJ (1975) Effects of hematin in hepatic porphyria. Further studies. Ann Intern Med 83: 20-30.

5. Jones SR, Bell A, Brink G2 (2014) Treatment of acute intermittent porphyria in the emergency department. J Emerg Nurs 40: 257-259.

6. Neely SM, Gardner DV, Reynolds N, Green D, Ts'ao CH (1984) Mechanism and characteristics of platelet activation by haematin. $\mathrm{Br} \mathrm{J}$ Haematol 58: 305-316.

7. Yamamoto S, Hirano Y, Horie Y (1993) Cimetidine reduces erythrocyte protoporphyrin in erythropoietic protoporphyria. Am J Gastroenterol 88: 1465-1466.
8. Fujita Y, Sato-Matsumura KC (2010) Effective treatment for porphyria cutanea tarda with oral cimetidine. J Dermatol 37: 677-679.

9. Horie Y, Udagawa M, Hirayama C (1987) Clinical usefulness of cimetidine for the treatment of acute intermittent porphyria--a preliminary report. Clin Chim Acta 167: 267-271.

10. Marcus DL, Halbrecht JL, Bourque AL, Lew G, Nadel H, et al. (1984) Effect of cimetidine on delta-aminolevulinic acid synthase and microsomal heme oxygenase in rat liver. Biochem Pharmacol 33: 2005-2008.

11. Horie Y, Norimoto M, Tajima F, Sasaki H, Nanba E, et al. (1995) Clinical usefulness of cimetidine treatment for acute relapse in intermittent porphyria. Clin Chim Acta 234: 171-175.

12. Cherem JH, Malagon J, Nellen H (2005) Cimetidine and acute intermittent porphyria. Ann Intern Med 143: 694-695.

13. Rogers PD (1997) Cimetidine in the treatment of acute intermittent porphyria. Ann Pharmacother 31: 365-367. 